\title{
Molecular Nanotechnology
}

National Cancer Institute

\section{Source}

National Cancer Institute. Molecular Nanotechnology. NCI Thesaurus. Code C20491.

A multidisciplinary field that focuses on the ability to eng ineer and manipulate functional systems at the molecular level. These systems are comprised of atomic units and are quantitated utilizing nanoscale measurements. 